\title{
Social cues and ideology
}

\section{Unpacking the adaptive significance of liberal-conservative behavioral differences}

\author{
Jordan Mansell, University of Oxford
}

\begin{abstract}
Research shows that individuals with liberal and conservative ideological orientations display different value positions concerning the acceptance of social change and inequality. Research also links the expression of different values to a number of biological factors, including heredity. In light of these biological influences, I investigate whether differences in social values associated with liberal and conservative ideologies reflect alternative strategies to maximize returns from social interactions. Using an American sample of Democrats and Republicans, I test whether information about shared and unshared social values in the form of implicit social attitudes have a disproportionate effect on the willingness of Democrats and Republicans to trust an anonymous social partner. I find evidence that knowledge of shared values significantly increases levels of trust among Democrats but not Republicans. I further find that knowledge of unshared values significantly decreases trust among Republicans but not Democrats. These findings are consistent with studies indicating that differences in ideological orientation are linked to differences in cognition and decision-making.
\end{abstract}

Key words: Ideology, values, traits, trust, experimental interaction, behavioral adaptation, political biology

A significant body of literature in the social sciences now recognizes that biological factors, as well as social factors, play an important role in the development and expression of political views. This research, falling generally under the heading of "political biology," shows that ideological orientation, among other political traits, can be predicted on the basis of (1) behavioral dispositions (2) cognitive strategies (3) neurological/physiological activity and (4) hereditary factors (for an extensive literature review, see Hibbing, Smith, and Alford). ${ }^{1,2,3,4,5,6,7}$ While research in political biology has made significant progress in identifying the biological components associated with ideological differences, it remains focused on quantifying the extent to which these components influence ideological expression (such as the extent to which genetics accounts for differences in values linked to ideological orientation).

Despite the realization that hereditary factors influence political values and attitudes, limited attention

doi: $10.1017 /$ pls.2017.29

Correspondence: Jordan Mansell, University of Oxford, Department of Politics and International Relations, Manor Road, Oxford OX1 3UQ, United Kingdom. Email: jordan.mansell@linacre.ox.ac.uk has been given by political scientists to developing a causal understanding of why the traits associated with ideological differences are expressed within the population..$^{8,9,10,11,12}$ More simply, research in political biology, and the social sciences more generally, has failed to critically engage with the importance of our evolutionary legacy for the structure of politics and political differences. ${ }^{13,14}$ In this article, I investigate the potential utility of the different behavioral traits associated with liberal and conservative ideological orientations. Using an experimental design informed by an evolutionary framework, I investigate whether the behavioral differences between liberals and conservatives reflect differences in sensitivity to socio-environmental cues that are consistent with alternative adaptive strategies to avoid socio-environmental risks. In particular, I focus on whether the observed behavioral differences in liberals and conservatives reflect alternative adaptive strategies to maximize returns from social interactions by minimizing the costs of exploitation. Maximization refers to the net benefits - gains minus losses - that individuals receive over a lifetime of social interactions.

In conducting this study, I have three objectives: first, to expand current research on the behavioral differences 


\section{Social cues and ideology}

associated with ideological orientation; second, to observe how these differences impact social interaction in general; and third, to lay a foundation for a larger theoretical discussion on the ultimate evolutionary causes of these different traits. Next, I review the literature on the traits associated with liberal and conservative ideological orientations before developing the theoretical framework and experimental design.

\section{Values, traits, and ideology}

Recent publications have brought renewed attention to values as the "critical determinants" of ideological orientation and political behavior by demonstrating that values are key predictors of behavior across a wide spectrum of political and cultural groups. ${ }^{15,16,17,18}$ Puriko, Schwartz, and Davidov find that among Western European countries, values for universalism and benevolence and for conformity and tradition more strongly predicted political orientation than sociodemographic factors. ${ }^{19}$ Thorisdottir et al. find that values for traditionalism, order, and adherence to rules strongly predicted a right political orientation among Western and Eastern European countries. ${ }^{20}$ Smith et al. find that implicit social attitudes - a measure of social values concerning equality and universalism, conformity and traditionalism, leadership, and the punishment of rule breakers - strongly predicted ideological orientation across a liberal-conservative scale. Finally, a meta-study by Jost et al. reviewing 88 publications from more than 12 countries concluded that differences in liberal and conservative ideological orientations are related to two key factors: tolerance of social change and intolerance of inequality. ${ }^{21,22,23}$ Taken together, the results of these studies suggest that the liberal-conservative dimension of the ideological spectrum may reflect a core set of universal social intuitions that contribute to the formation of ideological differences. ${ }^{24,25}$

The claim that the ideological spectrum revolves around a set of universal values is further supported by recent studies on the genetic influences on social behavior, which find that many of the social values used to predict ideological orientation are also influenced by hereditary factors. A recent twin study by Hatemi et al. involving nine samples taken from five countries finds that many of the values that predict liberal-conservative ideological orientation, such as life values and measures of authoritarianism, egalitarianism, individualism, collectivism, equality and freedom, all "contain a common genetic influence." ${ }^{26}$ Combined with the results of other twin studies indicating that many political attitudes associated with ideology are also heritable, these findings suggest not only that ideology is a social phenomenon but also that the structure and expression of ideology may have links to our evolutionary past. ${ }^{27,28,29,30,31,32}$

The idea that the structure and expression of politics has been influenced in some way by evolutionary pressures is further supported by studies on the cognitive, psychological, and neurological behaviors of liberals and conservatives. These studies find that these groups, broadly defined, have significant differences in their sensitivities, and responses to, socio-environmental stimuli. ${ }^{33}$ For example, in a study involving an exploratory learning task, Shook and Fazio find that in comparison to liberals, conservative individuals employed a focused learning strategy and were more likely to learn from negative responses. Liberals, in comparison, employed a more general learning strategy that sampled from a larger range of options but was less effective at remembering previously sampled items. ${ }^{34}$

Research by Amodio et al. into differences in cognitive processing between liberals and conservatives finds that, compared with conservatives, liberals have a more flexible cognitive style, being more likely to change habitual responses during a go/no-go task when presented with a novel stimulus. ${ }^{4}$ By comparison, during the same go/no-go task, conservatives used a more fixed response style, being more likely to rely on a habitual response when primed with a novel stimulus. The authors conclude that differences in ideological orientation are linked to differences in cognitive control and self-regulation.

A study by Kanai et al. using functional magnetic resonance imaging (fMRI) demonstrated that gray matter volume in key brain areas related to conflict processing differs in liberals and conservatives. The authors find that greater liberalism is associated with increased volume in the anterior cingulate cortex, an area of the brain associated with affective decision-making, while greater conservatism is associated with greater volume in the right amygdala, an area of the brain associated with negative emotional processing. ${ }^{5}$

A study by Oxley et al. finds that individuals who displayed a greater sensitivity to negative and threatening stimuli also supported higher levels of military spending, an attitude position associated with a conservative ideological orientation. In comparison, individuals who had a much lower sensitivity to these negative stimuli were more likely to support foreign aid 


\section{Mansell}

and welfare spending, an attitude position associated with a liberal ideological orientation. ${ }^{2}$ While the causal direction of these effects has yet to be determined, the findings are consistent with the view that liberal- and conservative-oriented individuals may differ in their sensitivities to socio-environmental stimuli. It is also worth noting that previous studies on the heritability of political differences find that attitudes in support for both military spending and foreign aid are linked to hereditary influences. ${ }^{27}$

In a second fMRI study, Schreiber et al. examine differences in brain activity/oxygenation in liberals and conservatives during a risk-taking task. They find that although risky behavior did not differ between liberals and conservatives, the brain activity associated with this behavior did differ. ${ }^{6}$ Liberals showed significantly greater activity in the left insula cortex, while conservatives showed significantly greater activity in the right amygdala. The left insular cortex is involved in the representation of internal bodily cues for subjective feeling states and emotional regulation related to signaling potential changes in interceptive states as well as to changes in possible decision-related outcomes. Activity in the right amygdala is linked to the processing of negative emotional stimuli. The authors conclude that liberals and conservatives engage different cognitive processes when they think about risk. Liberals focus more on internal psychological states, while conservatives focus on external and negative factors. As the part of the brain associated with affective decision-making, the greater level of activity in the insular cortex during risky decision-making suggests that liberal individuals may have a greater potential to update and change their decision-making process after receiving new information. Furthermore, the greater levels of amygdala activity and lower levels of insular activity observed in conservatives suggest that conservatives are more focused on threat-related outcomes and may be less likely to update their decision-making process under novel environmental conditions. Importantly, these results are consistent with the findings of Amodio et al. and Kanai et al. that liberals and conservatives show differences in their sensitivity or responses to different environmental stimuli and differences in the activation of cognitive regions important for cognitive control and self-regulation.

Finally, studies on the personality traits associated with ideological orientation find that conservatives are more likely to express conscientiousness (the concern for correct behavior) as well as intolerance of ambiguity and a greater need for cognitive closure; liberals, meanwhile, are more likely to express openness to experience (the desire for new sensation seeking). ${ }^{1}$ These results further support the argument that liberal- and conservative-oriented individuals may seek out, and respond to, environmental experiences in different ways.

Taken together, the combination of behavioral traits and hereditary influences associated with differences in ideological orientation strongly suggests that there is an underlying behavioral dimension to the ideological spectrum that has been shaped by evolutionary factors.

\section{Building an evolutionary framework: The social risk bypothesis}

Based on differences in sensitivity to negative stimuli, affective decision-making, cognition, personality traits, and the influence of hereditary factors on political values, one explanation for the behavioral traits associated with liberal and conservative ideologies is that these orientations reflect alternative adaptive strategies to maximize returns from social interaction. ${ }^{35,36}$ Adaptation refers to the utility of a trait to produce beneficial social outcomes in response to different environmental conditions. Drawing from the theory of motivated social cognition developed by Jost et al. and the theories of reciprocal altruism and indirect reciprocity developed by Trivers, I develop the social risk hypothesis (SRH) to account for the evolution of the different social values associated with liberal and conservative ideologies in terms of their contribution to individual social utility under a range of different environmental conditions. ${ }^{37}$ The SRH argues that differences in social values associated with ideological orientation are the result of differences in heritable dispositions whose function is to maximize returns from social interaction by minimizing the individuals costs of exploitation. Maximization refers to the ability of a trait to produce the greatest possible gains - benefits minus losses - over an indefinite number of social interactions. Next, I review the theories of motivated social cognition and reciprocal altruism before fully developing the predictions of the SRH.

The theory of motivated social cognition argues that liberal and conservative political orientations are based on two dimensions of social behavior: the tolerance of social change and the tolerance of inequality. ${ }^{38}$ Whereas traditional approaches in political science, such as the Michigan school, rational choice theory, or social constructivism, see ideological orientation as resulting from the effects of socialization or the pursuit of conscious 


\section{Social cues and ideology}

interests, motivated social cognition sees ideological orientation as driven by individuals' cognitive and emotional needs. ${ }^{23,39}$ Based on a meta-analysis of 88 research samples conducted in 12 countries over a period of 40 years, Jost argues that these two psychological dimensions - the tolerance of social change and tolerance of inequality - are part of the human cognitive apparatus that underlies ideological differences.

Adopting a dispositional approach to behavior and ideological orientation, Jost's model assumes that "individuals gravitate" toward the ideas and behaviors that "match" or "resonate" with their own psychological needs, or sensitivities. ${ }^{40,41}$ Based on this model, Jost hypothesizes that conservative orientations are favored by individuals possessing strong needs to manage the effects of threat and uncertainty and to simplify the conditions of their external environment. By comparison, a liberal orientation is favored by individuals with lower psychological needs to balance the effects of threat or uncertainty but a greater desire to maintain an egalitarian social environment.

Threat and uncertainty refer to a need to manage two factors: a desire to manage external threats from predation or other social actors and a desire to minimize one's personal sense of helplessness or existential doubt. Observing that conservative-oriented individuals are less tolerant of change and more tolerant of inequality, including social dominance and hierarchy, Jost suggests that "preserving the (inegalitarian) status quo allows one to maintain what is familiar and known while rejecting the risky, uncertain prospect of social change." 42 Within the motivated social cognition model, conservative individuals seek to minimize the costs of cognitive processing and psychological stress associated with complex environments. Alternatively, liberal orientation is reflective of individuals with lower sensitivity to threat and uncertainty as well as higher needs for complex cognition, imaginative thinking, and a sensitivity to inequality. ${ }^{38}$

While Jost's hypothesis is consistent with research findings in social psychology, the argument that conservative political orientations emerged as a result of psychological motivations to reduce feelings of threat and uncertainty is incomplete. Missing from his position is a mechanism to explain why subjects are interested in simplifying their environment beyond a purely psychological need and why the two dimensions of social behavior he identifies - the tolerance and intolerance of social change and of inequality - are important to this process. Furthermore, the motivated social cognition model fails to offer a full account for the existence of liberal identities, such as why individuals should develop a psychological need for egalitarian social environments. Equally problematic is that, from an evolutionary perspective, Jost fails to provide an explanation for why human behaviors should include the two competing sets of behavioral dispositions he identifies.

While liberal identities are viewed as a product of a reduced sensitivity to threat, a desire to engage in more sophisticated cognition, and a sensitivity to inequality, the mechanism that drives the psychological need for these behavioral characteristics is never fully developed within the motivated social cognition model. Although research in psychology and social psychology is often assumed to have a biological-evolutionary basis, in this instance, little attention is given to unpacking how the behaviors and dispositions associated with conservative and liberal political orientations can be viewed as a natural response to the conditions of the external environment, such as why these two sets of dispositions exist and how they benefit individual utility.

One explanation for the evolution of preferences for social environments that are stable and simplified and for those that are normatively flexible and egalitarian is that these conditions contribute to the maintenance or occurrence of altruistic behaviors among social actors. ${ }^{43}$ Developed by Trivers, the theory of reciprocal altruism is an evolutionary mechanism that attempts to explain the evolution of cooperative behaviors between nonrelated actors. Trivers defines reciprocal altruism as a behavior wherein an individual acts in way that temporarily reduces his or her own fitness while increasing another individual's fitness, with the expectation that the other individual will reciprocate this gesture at a later time. ${ }^{37}$ Trivers argues that when the cost of an "altruistic" action is less then the potential long-term benefits from reciprocation, altruistic behaviors will evolve in a population. The second theoretical component to explain the evolutionary origin of social interactions is the theory of indirect reciprocity. Whereas reciprocal altruism relies on repeated encounters between the same subjects, indirect reciprocity relies upon the reputations of subjects within social groups to act as cues to trustworthiness. ${ }^{44,45}$ Instead of the same two individuals interacting repeatedly, third parties can make inferences about subjects' trustworthiness based on observations of their previous social interactions. This model requires that subjects be able to observe and monitor the changing social network of the group in order to keep track of subjects' reputations. ${ }^{44}$ 


\section{Mansell}

Studies on social behavior demonstrate that the ability to track or maintain reputations can have a significant impact on levels of social interaction within a social group. ${ }^{46,47,48,49}$

Accordingly, Trivers's ideas of reciprocal altruism and indirect reciprocity may explain the evolutionary mechanisms underlying Jost's hypothesis about motivated social cognition. Placed in the evolutionary framework, dispositions toward the tolerance of social change and the tolerance of inequality may reflect adaptive behaviors if these behaviors contribute to individual fitness through the frequency of returns from beneficial social interactions. For example, if preferences for stable, normative, structured, and hierarchical social environments increase beneficial social interactions by allowing individuals to select on social partners by tracking the behaviors of individuals in a social group, normalizing or coercing reciprocation following a cooperative action, or increasing general participation in communal goods, then it is possible that dispositions for these behaviors could evolve within a population. ${ }^{50,51}$ Similarly, if high levels of inequality are adversely affecting social interactions that are important to individual fitness, then dispositions for the intolerance of inequality may evolve in a population. For example, high levels of inequality are detrimental to individual utility if they cause individuals to withhold reciprocity or decreases in contributions to communal goods. ${ }^{52,53}$

Based on the models of motivated social cognition, reciprocal altruism, and indirect reciprocity, as well as research on the different traits associated with liberals and conservatives, the SRH argues that differences in liberal and conservative ideological orientations reflect alternative adaptive strategies to maximize returns from social interaction. Conservative individuals are applying a threat-sensitive social strategy that is highly averse to the costs of social exploitation. Within this model, conservative individuals maximize social returns by avoiding the costs of exploitation, decreasing their level of social investment in response to negative cues about the trustworthiness of a potential partner. In comparison, liberal individuals are applying a social strategy that is risk accepting in that it attempts to fully develop each discrete opportunity for social interaction. Liberal individuals maximize social returns by taking full advantage of potentially beneficial social opportunities, increasing their level of social investment in response to positive cues about the trustworthiness of a potential partner.
The SRH argues that as part of a loss-averse strategy that aims to avoid the costs of exploitation, conservative individuals develop a greater sensitivity to negative or "threatening" stimuli, which allows them to identify or avoid unfavorable interactions. ${ }^{4,5,6}$ Across a variety of social interactions, conservative individuals should display a consistent level of social trust, however, in response to a negative cue conservatives' trust should significantly decrease. The advantage, or adaptation, of this strategy is that it minimizes potential losses from exploitation that can be obtained in any single interaction. Losses from exploitation can be highly damaging to individual fitness. ${ }^{23}$ The disadvantage of this strategy is that, because of their increased sensitivity to threat, conservative-oriented individuals maybe more discriminating in their social interactions and consequently may fail to capitalize on beneficial opportunities. Within the SRH, conservative individuals develop preferences for stable, normative, and well-structured social environments, as these conditions simplify environments allowing for the identification of potential threats through the monitoring of behavior and reputation of other social actors. ${ }^{14,44}$

By comparison, the SRH argues that liberal individuals are applying a strategy that attempts to maximize opportunities for social interaction. Compared with conservatives, liberal individuals, who have a greater cognitive flexibility, are more sensitive to social cues indicating a partner's willingness reciprocate. Consequently, in response to a positive cue, liberal individuals are more likely to participate in a social interaction or to increase their levels of social investment. ${ }^{5,6}$ The disadvantage of this strategy is that by increasing the frequency or degree of their social contributions in response to cues, liberal individuals are more vulnerable to the costs of exploitation. ${ }^{35}$ Within the SRH, liberals' preferences for egalitarian and nonhierarchical social environments are not viewed as motivated by concern for the welfare of others within a social group but by a concern for personal fairness, the personal desire to obtain social reciprocity.

\section{Theoretical assumptions}

In this experiment, the ability to draw conclusions about the evolutionary influences on political ideology depends on the relationship between political values, orientation, and heredity. This logic follows from the principles of the phenotypic gambit (see the next section): because the evolution of a trait is connected to its utility - defined as the contribution it makes to an 


\section{Social cues and ideology}

organism's reproductive success - given a trait with a known heritability, it is possible to obtain insights into a trait's utility by observing how this trait affects behavior within an environment. ${ }^{54,56}$ By experimentally manipulating environmental conditions interacting with heritable traits, such as political values, and measuring how an organism's behavior changes or benefits in response to different conditions, it is possible to gain insights into the trait's utility and therefore to understand something about why this trait evolved. This approach assumes that some characteristic associated with different values is, or has previously been, adaptive. The objective of this research is therefore to evaluate experimentally what these potential adaptive properties could be.

A second experimental assumption is that the behavioral differences of liberals and conservatives have a specific utility for social interaction. This assumption is based on a review of the literature on the behavioral traits, dispositions, and social values associated with liberal and conservative orientations, as well as how these dispositions are shown to influence behavior in social contexts. ${ }^{12}$ Given that political differences also reflect social differences, or different opinions on social issues, understanding whether the traits associated with political differences evolved for specific social utilities is an important theoretical question with implications for future discussions on politics and political behavior. However, I recognize that determining whether the different traits associated with ideological orientations are specifically adaptive for social behavior is beyond the scope of this study, as care must be taken to rule out alternative explanations. For example, future studies must investigate the possibility that these differences are a product of general environmental adaptations as opposed to adaptations for social interaction.

Consequently, the possibility that liberal and conservative differences are not specifically adaptive has a minimal impact on this research as the primary purpose of this experiment is to explore the possible evolutionary influences to the ideological spectrum. It is therefore expected that future research will result in revisions to the SRH behavioral model and provide a clearer picture of what, if any, are the evolutionary influences on the ideological spectrum.

\section{Understanding the phenotypic gambit}

The study of political ideology as a product of evolution relies on the heritability of political values as a justification for the influence of evolutionary selection on the ideological spectrum. Within this framework, no attempt is made to separate the influence of genetic and environmental factors on the expression of political values. ${ }^{55}$ Instead, to compensate for the inability to separate the interaction between genes and environment, I rely on a methodological assumption called the "phenotypic gambit."

An important concept in the study of behavior in the life and evolutionary sciences, the phenotypic gambit states that when studying a trait with established heredity, this trait may be treated as an evolutionary adaptation and detailed assumptions about the extent of the trait's heredity, such as the extent to which a trait is influenced by social versus genetic factors, may be avoided. The phenotypic gambit works by hypothesizing that in the function of a hereditary trait, some "underlying strategies or decision rules" have been shaped by the process of selection resulting in a trait whose expressed function is adaptive. ${ }^{25}$ This approach to studying adaptation assumes that it is "neither necessary nor feasible to demonstrate the exact heritable basis of every trait"; instead, researchers continue as though the precise "link" between heritability and phenotype (whether it is caused by a single or by several genes), is unimportant. ${ }^{25}$ Noteworthy is that this "gambit" is based on two further assumptions: that selection will favor traits with high fitness regardless of the "particulars of their inheritance and that the proxies employed to measure the traits' adaptive significance (e.g., time per calories earned) strongly correlate to individual fitness. ${ }^{25}$

This research applies the assumptions of the phenotypic gambit in two ways. First, it assumes that the individual rewards from social interactions involving trusting and cooperative behaviors are sufficiently beneficial as to be treated as proxies for individual fitness. Second, based on the heritability of the values associated with liberal and conservative orientations, it is assumed that these values, or some correlated behaviors or dispositions, are the product of natural selection and therefore have evolved to fulfill some kind of adaptive function.

Based on these assumptions, this research makes no attempt to disentangle the contributions of genetic and environmental factors to behavior. Both are understood to be important, and interacting, influences on behavioral expression..$^{55}$ Instead, it proceeds according to the assumptions of the phenotypic gambit: that some underlying aspects of the traits being studied are the result of adaptive selection. This research assumes that political values, or the associated behavioral dispositions, convey 


\section{Mansell}

some adaptive benefit for survival and reproduction. The goal of this research is therefore not to prove that liberal and conservative political values and orientation are influenced by evolution but to investigate the plausible adaptive benefits of the traits associated with liberal and conservative ideological orientations. By examining how individuals respond to information about values, I hope to understand more about why these values, or a subset of correlated behaviors, evolved in the human lineage.

\section{Social risk bypotheses}

In the following experiment, I expose liberal- and conservative-oriented individuals to different cues about a potential social partner and observe the effect of these cues on their willingness to engage in a risky social interaction - a trust game. Based on the preceding arguments, the SRH makes the following predictions about trust behaviors of liberals and conservatives in response to treatment.

H1: Compared with the control (no information condition), trust in liberal-oriented but not conservative-oriented individuals will increase in response to a social cue that a partner shares similar social values.

H2: Trust in liberal-oriented compared with conservative-oriented individuals will be significantly higher in response to a social cue that a partner shares similar social values for normatively flexible and egalitarian social environments.

H3: Compared with the control, conservativeoriented individuals will display decreased levels of trust in response to a social cue that a partner displays dissimilar social values (values for normatively flexible and egalitarian social environments).

In addition to social values, this experiment also manipulates cues about the shared and unshared social and political identities of a potential social partner. The purpose of these treatments is to provide a meaningful comparison of the effect of shared identity on trust in liberals and conservatives (see the Treatments section). However, because political identity is tied to complex social factors (including group competition, which is known to influence group cooperation), it is difficult to predict whether unshared political identity will have a negative effect on trust among conservative

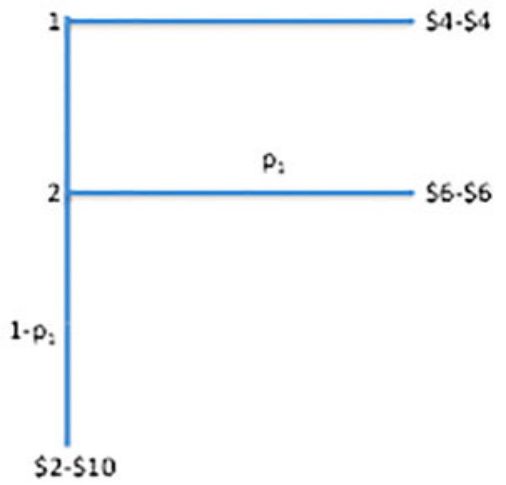

Figure 1. Trust game Structure.

participants. ${ }^{56,57}$ As a result, no explicit prediction is made with respect to political identity. However, observing an increase in trust in liberal-oriented but not conservative-oriented individuals in response to shared identity would be consistent with the predictions of the SRH that liberal-oriented individuals have greater cognitive flexibility and are more responsive to positive social cues. ${ }^{4,5,6}$ Similarly, a decrease in trust in conservative but not in liberal individuals would also be consistent with the predictions of the SRH that conservative individuals are more sensitive to negative stimuli.

\section{Experimental methods}

To evaluate the potential adaptive utility of ideological orientation, participants play a dichotomous one-shot trust game in which they are matched with an anonymous social partner. The trust game is modeled after the voluntary trust game developed by McCabe, Rigdon, and Smith. ${ }^{58}$ Participants are randomly assigned to one of two player positions, where Player 1 is "the decider" and Player 2 is "the allocator" (see Figure 1). At the start of the game, Player 1 is given the choice to "opt in" and play the trust game with his or her partner or "opt out" of the trust game. If Player 1 chooses to opt out, the game ends, and both players, Player 1 and Player 2, receive a fixed reward of US\$4. If Player 1 decides to opt in, the total available prize pool is increased from $\$ 8(\$ 4 / \$ 4)$ to $\$ 12$; however, the decision on how to allocate the funds is made by Player 2. Player 2 has the option to split the prize pool equally $(\$ 6 / \$ 6)$ or unequally $(\$ 2 / \$ 10)$. Player 1 is therefore faced with a dilemma: play the trust game for a chance at a higher reward, but with the risk of exploitation by the partner. Unknown to 


\section{Social cues and ideology}

participants is that all participants in the study are assigned to play as Player 1, and Player 2 is a computer confederate. The use of deception is a necessary to control participants' exposure to the same series of implicit attitudes. On average, participants completed the study in approximately 20 minutes.

The dichotomous measure is employed based on considerations about the kinds of adaptive problems humans evolved to overcome. Many social interactions requiring trust, cooperation, and coordination, such as group hunting, child care, and even food sharing, involve all-or-nothing considerations. ${ }^{59,60,61}$ In these conditions, the benefits to individuals are entirely dependent on positive returns, and the losses from investments may be substantial to individual fitness. ${ }^{23}$ Consequently, a simpler dichotomous outcome is employed. The utility of the trust game is such that participants should not cooperate with their partner if they believe there is a greater than $35 \%$ chance that the partner will not reciprocate.

\section{Treatments}

After receiving the experimental instructions, participants experience a 45 -second delay, at which point they are randomly assigned to complete one of six experimental treatments. In each treatment, participants receive different pieces of information about their partner. Random assignment is accomplished by block-treating participants according to self-reported political orientation across a 7-point left-right Likert scale and then randomly assigning individuals to a treatment. Left-right scales are used to coincide with the stimulus applied in Treatments 4 and 5, "Political Identity."

A multi-treatment approach is used to control for possible confounding related to in-group and out-group preferences by observing whether trust in liberals and conservatives is generally affected by conditions of minimal group identity. ${ }^{14,25,62}$ Furthermore, by manipulating the type of social cue presented to participants, I am able to evaluate the validity of the SRH by looking for trends in how individuals with different ideological orientations generally respond to socio-environmental cues. For example, comparing how trust in liberals and conservatives is affected by shared social values, shared political orientation, and shared preferences for a favorite sport can separate the effects of a specific shared identity (e.g., political orientation) from the effect of social information in general. In doing so, I hope to determine whether differences in ideological orientations are a product of differential responses to socio-environmental stimuli.

The treatments are as follows:

1. Treatment 1: Control

2. Treatment 2: Liberal Values

3. Treatment 3: Conservative Values

4. Treatment 4: Right Political Identity

5. Treatment 5: Left Political Identity

6. Treatment 6: Sport - In-Group

7. Treatment 7: Sport - Out-Group

In Treatment 1, "Control," participants receive no information before participating in the trust game. In the remaining six treatments, participants are presented with a series of questions, which they are informed are also being answered by their partner. After reviewing all of these questions, participants experience a 15 -second delay, after which they are presented with the responses given by their partner. In Treatments 2 and 3, "Values," participants are provided with their partner's responses to questions about their social values in the form of implicit social attitudes concerning the structure and function of the social group. In Treatment 2, these responses indicate strong support for socially flexible and egalitarian environments, which is consistent with a liberal ideological orientation. In Treatment 3, these indicate strong preferences for structured and normatively stable environments, which is consistent with a conservative ideological orientation.

In Treatments 4 and 5, "Political Identity," participants are informed of their partner's political orientation based on a 7-point Likert scale for left-right political orientation. A left-right political scale is used to evoke a sense of shared or unshared social values and political identity while avoiding a sense of out-group aggression that may be associated with the terms "liberal" and "conservative" within an American political context. In Treatment 4, partners indicate a right political orientation, and in Treatment 5, a left political orientation.

In Treatments 6 and 7, "Sport," participants are told that their partner is asked to answer the following question, "What is your favorite professional sport?" and that their partner is given the option to choose between MLB Baseball or NFL Football. In each case, 


\section{Mansell}

participants are informed that their partner's favorite sport is NFL Football. Within the statistical results, Treatment 6 represents a subgroup of participants who also indicated that they preferred NFL Football, and Treatment 7 represents all participants who indicated they preferred MLB Baseball (the opposite of their partner).

\section{Treatments 2 and 3: Social values treatments}

In Treatments 2 and 3, participants are provided with information about their partner's social values in the form of implicit social attitudes. ${ }^{25}$ While in some psychological contexts, "implicit attitudes" refers to a latency or bias in individuals' ability to associate certain ideas with concepts, in this context, it refers to a measure of social values about the appropriate structure and function of the social group, such as the nature of social rules, order, self-conduct, and identification of individuals within a social group. I use the "Society Works Best" measure developed by Smith et al. as a proxy for values for social change and inequality. This measure was developed to predict ideological affiliation based on individuals' implicit preferences for the structure and function of social environments. The measure examines individual preferences for (A) the appropriate role of traditional values and moral codes in social conduct; (B) the treatment of out-groups and rule breakers; (C) the nature and conduct of group leadership; (D) the role of individuals within the group; and (E) whether compromise or absolutism is the best approach to human relations. The measure is composed of 14 binary response questions, which are scored from 14 to 28 points. Within this sample, the results are coded such that a score of 14 is strongly associated with liberal ideological orientation, and 28 with conservative orientation. A standard logistic regression of this measure on political orientation in this sample (Democrat $=$ 1 , Republican $=2$ ) shows that higher scores on the implicit attitude measure are strongly correlated with Republican Party affiliation (Table 1).

Differences in the Society Works Best measure underlie specific value positions concerning the tolerance of social change and inequality. For example, preferences for an external moral code are related to preferences for normative stability. ${ }^{25}$ The value dimensions within the measure are also associated with a number of hereditary dispositions identified by the Wilson-Patterson Index, which are also strong predictors of ideological orientation. I use the Society Works Best measure to target behavioral differences that operate on a dispositional
Table 1. Logistic regression of implicit attitude measure on Democrat-Republican political orientation. Higher scores predict a republican orientation.

\begin{tabular}{cccrccc}
\hline \hline $\begin{array}{c}\text { Con-Lib } \\
\text { Preference }\end{array}$ & Coef. & Std. Err & \multicolumn{1}{c}{ Z. } & $P>|z|$ & \multicolumn{2}{c}{$\begin{array}{c}\text { 95\% Conf. } \\
\text { Interval }\end{array}$} \\
\hline WorksSum & 1.538 & 0.035 & 19.05 & 0.000 & 1.471 & 1.608 \\
Cons & 0.019 & 0.004 & -21.33 & 0.000 & 0.013 & 0.027 \\
\hline
\end{tabular}

Note: WorksSum is a continuous scale of the 14-28 point implicit attitude measure.

level, that is, on social intuitions below the level of partisan attachment.

The cues used in Treatments 2 and 3 consist of eight questions taken from the Society Works Best measure representing four of the five different social dimensions measured: (1) traditional values; (2) out-groups/rule breakers; (3) leadership styles; and (4) individuals/groups (see questions below). I focus on the four dimensions that Smith et al. show to have the strongest correlation to the Wilson-Patterson Index and self-placement. The full Society Works Best measure is listed in the Appendix (available in the online version of this article). ${ }^{25} \mathrm{~A}$ response of 1 is associated with a more conservative political orientation, while a response of 2 is associated with a more liberal orientation. These scores are reversed during the statistical analysis.

\section{Value Cues: Treatments 2 and 3}

Traditional Values/Moral Codes:

Society works best when ...

1. People live according to traditional values

2. People adjust their values to fit changing circumstances

Society works best when ...

1. Behavioral expectations are based on an external code

2. Behavioral expectations are allowed to evolve over the decades

Society works best when ...

1. Our leaders stick to their beliefs regardless

2. Our leaders change positions whenever situations change 


\section{Social cues and ideology}

Out-Groups/Rule Breakers:

Society works best when ...

1. We take care of our own people first

2. We realize that people everywhere deserve our help

Society works best when ...

1. Those who break the rules are punished

2. Those who break the rules are forgiven

Role of Group/Individual:

Society works best when ...

1. Every member contributes

2. More fortunate members sacrifice to help others

Leadership:

Society works best when ...

1. Our leaders are obeyed

2. Our leaders are questioned

Society works best when ...

1. Our leaders call the shots

2. Our leaders are forced to listen to others

Table 2 shows that there is a strong correlation between the implicit attitudes questions used as cues in Treatments 2 and 3 and political party affiliation.

\section{Survey and demographic questions}

Prior to the interaction, participants complete a 19point demographic questionnaire, including age, education, ethnicity, income, religious affiliation, religious observance, and political orientation. After the interaction, participants complete the full measure of implicit attitudes, the 21-question Wilson-Patterson Index, a 10-factor personality model, and a 17-question measure of affective intensity. ${ }^{63,64}$ A series of control questions are employed throughout the study to screen participants who are not answering questions truthfully.

Ideological orientation is assessed using multiple measures, including party affiliation (Democrat, Republican, other), a modified 21-question WilsonPatterson Index, and a 14-question Society Works Best measure. ${ }^{25}$ Ideological orientation within the sample is as follows: Democrat, $n=1,261(54.10 \%)$; other, $n=517(21.41 \%)$; Republican, $n=553(23.73 \%)$.
Table 2. Logistic regression of implicit attitude questions in treatment 2 on Democrat-Republican political orientation. Higher scores predict a Republican orientation.

\begin{tabular}{cccccccc}
\hline \hline $\begin{array}{c}\text { Rep-Dem } \\
\text { Preference }\end{array}$ & Coefficient Std. Err & \multicolumn{1}{c}{ Z. } & $P>|z|$ & \multicolumn{2}{c}{$\begin{array}{c}95 \% \text { Conf. } \\
\text { Interval }\end{array}$} \\
\hline WorksPrime & 1.825 & 0.059 & 18.76 & $0.000^{* *}$ & 1.714 & 1.944 \\
Cons & 0.031 & 0.005 & -21.50 & 0.000 & 0.022 & 0.042 \\
\hline
\end{tabular}

Note: WorkPrime is continuous scale of the 8-16 point implicit attitude measure based on the implicit attitude questions used as cues in Treatments $2 \& 3$.

\section{Participant sample}

Participants were recruited from three online participant services: (1) Amazon Mechanical Turk (MTurk), (2) FindParticipants.com, and (3) SocialSci.com. The sample was restricted to U.S. residents over the age of 18. Participants were asked to take part in an online "Survey and Experiment" in which they would complete an interaction with another study participant. Participants were told the study would take between 20 and 25 minutes to complete and that they could earn between $\$ 2$ and $\$ 10$ based on their decisions during the interaction. The experiment was programmed and implemented using the online research tool Qualtrics. Experimental trials were conducted between October 2014 and May 2015.

Research from Berinsky, Huber, and Lenz and Beramendi, Duch, and Matsuo shows that the behavior of participants recruited from online study pools such as MTurk closely approximates the behavior of in-lab participants and that online and in-lab participants display similar behaviors in response to the same experimental task. ${ }^{25,65,66}$ As this study is interested in the disposition of ideological subjects toward positive and negative cues, an online environment was the ideal location to conduct this study as it minimizes possible confounds related to direct, face-to-face interactions, such as participants' attractiveness, gender, socialization prior to treatment, or ethnic identity.

During the study, approximately 4,200 participants logged in to the experiment. A total of 2,461 participants completed the study. From the sample of 2,461 participants, 45 participants were identified by their IP address as having completed the study more than once; therefore, these individuals were dropped from the statistical analysis. Three participants were removed for declaring in the participant feedback section that they did not believe they were participating with another person during the study. During one of the trials, 


\section{Mansell}

an error occurred in which the educational information of 360 participants was not correctly recorded. These participants were contacted by the researcher and asked to provide their educational information. Participants were offered an additional \$1 for doing so. From the 360 participants who experienced the error, all but 82 responded to the email requesting their educational background. These 82 participants were dropped from the statistical analysis. The final number of participants was 2,331: MTurk, $n=889$ (38.14\%); FindParticipants.com, $n=697$ (29.90\%); SocialSci.com $n=745(31.91 \%)$. The mean $S D$ age is $34(11.47)$. Sex ratio of the study was men, $n=1,073(46.03 \%)$, female, $n=1,258(53.97 \%)$.

\section{Deception}

During the study participants were told that they would be interacting with another survey participant; in reality no other participant existed. Unbeknownst to them, all participants in the interaction were assigned to play as Player 1. This action constituted deception on the part of the experimenter. Deception is crucial in this experiment, following psychological protocol, in order to elicit behavioral effects as responses to the targeted social values. Participants were fully debriefed by email at the end of the study. At the end of the study, no participant objected to the use of deception.

\section{Statistical approach}

Results are calculated using a binary logistic regression of a heterogeneous model, with clustered standard errors. The dependent variable is trust, coded as $1=$ trust and $0=$ no trust. Standard errors are clustered around the online recruitment platform. The platform is coded as a three-level categorical variable, with MTurk as the reference category. Effects are calculated as a two-way interaction between ideological orientation and treatment using a Lincom function. Lincom functions are used to compute point estimates, standard errors, and $p$-values for linear combinations of coefficients based on a fitted model. The Lincom command allows for measurement of effect sizes while accounting for initial differences in trust in the control treatment.

In analyzing the experimental results, I consider both the within- and between-subjects effects. Withinsubjects effects report the difference in trust for individuals with the same ideological orientation between the control and treatment conditions. Between-subjects effects report differences in trust for individuals with the different ideological orientations by looking at the change in trust between the control and treatment for each ideological group and comparing these differences. This approach is analogous to a differences-indifferences statistical model.

Treatment is coded as a categorical variable, labeled 1-7. The Control treatment is coded as the reference category. In analyzing the experimental results, ideological orientation is assigned by political party affiliation (Democrat, Republican, other). Political party affiliation is an established proxy of liberal-conservative ideological orientation within a U.S. sample. ${ }^{67}$ Party affiliation is chosen to capture ideological orientation to coincide with the sampling algorithm of SocialSci.com, which was programmed to oversample conservative participants based on political party affiliation. Using party identification also avoids issues with the reliability and subjectivity of self-reported ideological orientation by providing two salient identifiers of individuals' relative ideological orientation. As this experiment is interested in identifying possible behavioral differences underlying the liberal-conservative dimension of the ideological spectrum and not the efficacy of self-report measures, this decision is appropriate. As an added measure of robustness, the results are presented based on individual scores on the implicit attitude measure, which captures individual's values toward the structure and function of the social group. Democrat is coded as the reference category (Democrat $=0$, Republican $=1$ ).

In the statistical analysis, ideological orientation is coded as a three-level categorical variable $(1=$ Democrat, $2=$ Republican, $3=$ other), with Democrat as the reference category.

As an additional check on the validity of the SRH, I present the statistical results with ideology scored according to scores on the implicit attitude measure. I regress each of the five implicit attitude dimensions separately. Participants are grouped into categories based on their score in each of the five dimensions. I use the same regression model to measure the effects for Democrats and Republicans. As this regression is meant as an additional check on the validity of the experimental results, I focus on the within-subjects effects.

\section{Models}

The empirical results are presented across four statistical models, labeled A-D. Models are presented as odds ratios for trust in each treatment. Model A is a strict interpretation of randomized experimental trials with clustered standard errors. Model B includes control variables for age, education, ethnicity, income, 


\section{Social cues and ideology}

religious observance, sex, sexual orientation, and an interaction between sexual orientation and political party. Model C includes all control variables plus a measure of the "big five" personality traits. A measure of personality traits is included to control for a possible confounding between personality traits sensitive to treatment. Model D includes Model C plus a continuous variable that controls for a potential change in trust between the first and last experimental trials, which were conducted over a seven-month period.

The seven-month trial period reflected difficulties in recruiting a sufficient number of conservative participants from SocialSci.com and FindParticipants.com. To address this problem, an additional sample of participants from MTurk was recruited in January 2015, four months after the initial trials, to increase the overall numbers of participants. As a result, the variable that controls for the time in Model D is strongly correlated with participant platform. Consequently, when drawing conclusions based on the statistical models, I place greater weight on the consistency of effects across Models A-C. Participants in all three samples were recruited according to the same criteria.

In interpreting the statistical results, I focus on the consistency of results across the models. Model fit is tested using Hosmer-Lemeshow tests, Pearson's $\mathrm{X}^{2}$ goodness-of-fit, and ROC analysis. The covariance of the control variables is tested to identify any potential confounding factors (see the Appendix). The contribution of each individual control variable to the models is evaluated using Wald and likelihood tests (see the Appendix). A full listing of all experimental results is listed in the Appendix. A full comparison of the effect of each treatment with all other treatments, in Models A-D, is also listed in the Appendix.

\section{Experimental results}

\section{Summary of results}

The overall experimental results closely resemble the predictions of the SRH. As predicted by the SRH in $\mathrm{H} 2$ and $H 3$, trust in Democrats shows consistent and significant positive response to Treatment 2, "Liberal Values," and Treatment 5, "Left Political Identity" (Table 4, Figure 3). Also, as predicted by the SRH in H1, trust in Republicans shows a significant negative effect in response to Treatment 2 , "Liberal Values" $(0.878)$ ( $p<$ $0.050)$, as well as Treatment 7 "Sport - Out-Group" (0.418) $(p<0.050)$ (Table 6, Figure 4). Overall, in response to information about an anonymous partner, no significant negative effects are observed in Democrats and no consistent positive effects are observed in Republicans (see Tables 4-6).

With respect to $H 2$ and $H 3$, in Treatment 2, "Liberal Values," Democrats show a highly significant increase in trust in response to values toward normatively flexible and egalitarian social environments (Table 4). This effect is significant relative to the control $(p<0.001)$ and in comparison to levels of trust in Republicans in the same treatment $(p<0.050)$ (Table 5). The effect of these values on trust is also larger in comparison to shared minimal group identity, a preference for a favorite sport in Treatment $6(p<0.050)$ (Table 7). Additionally, as predicted by the SRH in H1, trust in Republican participants shows a significant negative effect in Treatment 2, "Liberal Values," relative to the control (Table 6). Also, as predicted by the SRH, no increase in trust is observed in Republican participants in response to Treatment 3, "Conservative Values."

In response to Treatment 5, "Left Political Identity," Democrats also display an increase in trust relative to the control. While this effect fails to reach significance in Model A, it does reach significance in Models B-D between $90 \%$ and $95 \%$ confidence levels (Table 4). The difference in trust between Democrats and Republicans in Treatment 5, "Left Political Identity," also reaches significance at the $99 \%$ confidence level $(p<0.001)$ (Table 5). No significant differences are observed in the levels of trust in Republicans in response to Treatments 4 and 5 relative to the control treatment. The only significant increase in trust in Republicans, relative to the control, is observed in Model D of Treatment 6, "Sport - In-Group" (Table 6); however, this effect is not significant across Models A-C.

Together, these results are consistent with the expectations of the SRH that liberal- and conservativeoriented individuals are differentially sensitive to positive and negative stimuli as part of alternative adaptive strategies to avoid the socio-environmental risks, such as the costs of exploitation. Next, I review the full experimental results with respect to the hypotheses of $\mathrm{SRH}$ in each treatment.

\section{Control treatment}

In Treatment 1, the control treatment, levels of trust among Republicans are higher in comparison to Democrats. This effect reaches significance at the $99 \%$ confidence level $(p<0.001)$ across all four statistical models (Table 3$)$. 
Table 3. Difference in levels of trust in control treatment by political dimension.

\begin{tabular}{ccccc}
\hline \hline \multirow{2}{*}{ Model } & Model A & Model B & Model C & Model D \\
& Odds Ratio & Odds Ratio & Odds Ratio & Odds Ratio \\
\hline Pol-Other & $0.809^{* * *}$ & $0.798^{* * *}$ & $0.789^{* *}$ & $0.811^{* * *}$ \\
& $(0.038)$ & $(0.191)$ & $(0.062)$ & $(0.049)$ \\
Pol-Republican & $1.546^{* * *}$ & $1.267^{* * *}$ & $1.372^{* * *}$ & $1.390^{* * *}$ \\
& $(0.095)$ & $(0.086)$ & $(0.054)$ & $(0.030)$ \\
\hline
\end{tabular}

Note: Brackets Denote Standard Errors. ${ }^{*}=<0.100,{ }^{* *}=<0.05$, $* * *=<0.001$.

Table 4. Comparing levels of trust in Democrats to Democrats in control treatment.

\begin{tabular}{ccccc}
\hline \hline $\begin{array}{c}\text { Model Pol Party } \\
\text { Democrat }\end{array}$ & $\begin{array}{c}\text { Model A } \\
\text { Odds Ratio }\end{array}$ & $\begin{array}{c}\text { Model B } \\
\text { Odds Ratio }\end{array}$ & $\begin{array}{c}\text { Model C } \\
\text { Odds Ratio }\end{array}$ & $\begin{array}{c}\text { Model D } \\
\text { Odds Ratio }\end{array}$ \\
\hline Treatment 2 & $2.573^{* * *}$ & $2.595^{* * *}$ & $2.616^{* * *}$ & $2.682^{* * *}$ \\
& $(0.532)$ & $(0.610)$ & $(0.649)$ & $(0.711)$ \\
Treatment 3 & 0.755 & 0.723 & 0.721 & 0.714 \\
& $(0.230)$ & $(0.243)$ & $(0.231)$ & $(0.233)$ \\
Treatment 4 & 1.045 & 1.111 & 1.170 & 1.383 \\
& $(0.472)$ & $(0.527)$ & $(0.498)$ & $(0.424)$ \\
Treatment 5 & 2.246 & $2.503^{*}$ & $2.621^{*}$ & $3.106^{* *}$ \\
& $(1.212)$ & $(1.426)$ & $(1.436)$ & $(1.176)$ \\
Treatment 6 & 1.506 & 1.579 & 1.583 & $1.932^{* *}$ \\
& $(0.558)$ & $(0.679)$ & $(0.613)$ & $(0.607)$ \\
Treatment 7 & 0.630 & 0.697 & 0.736 & 0.862 \\
& $(0.328)$ & $(0.400)$ & $(0.398)$ & $(0.324)$ \\
\hline
\end{tabular}

Note: Brackets Denote Standard Errors. ${ }^{*}=<0.100,{ }^{* *}=<0.05$, $* * *=<0.001$.

\section{Value treatments: Treatments 2 and 3}

As predicted by the SRH, in Treatment 2, "Liberal Values," trust in Democrats significantly increases. This effect reaches significance at the $99 \%$ confidence level across Models A-D $(p<0.001)$ (Table 4). In Treatment 3, "Conservative Attitudes," trust in Republicans shows a negative trend relative to the control; however, this effect fails to reach significance (Table 6). Consequently, for H1, I reject null; compared with the control (no information condition), trust in liberal-oriented but not conservative-oriented individuals will increase in response to a social cue that their partner shares similar social values.

Looking at the between-subjects effects, contrasting the effect of treatment with the effect of the control for each group, in comparison to Republicans, trust in Democrats significantly increases in Treatment 2, "Liberal Values." This effect reaches significance at the 95\% confidence level $(p>0.050)$ across Models A-D
Table 5. Comparing levels of trust in Republicans to Democrats in each treatment.

\begin{tabular}{ccccc}
\hline \hline $\begin{array}{c}\text { Model Pol Party } \\
\text { Republican }\end{array}$ & $\begin{array}{c}\text { Model A } \\
\text { Odds Ratio }\end{array}$ & $\begin{array}{c}\text { Model B } \\
\text { Odds Ratio }\end{array}$ & $\begin{array}{c}\text { Model C } \\
\text { Odds Ratio }\end{array}$ & $\begin{array}{c}\text { Model D } \\
\text { Odds Ratio }\end{array}$ \\
\hline Treatment 2 & $0.527^{* *}$ & $0.442^{* * *}$ & $0.452^{* * *}$ & $0.463^{* *}$ \\
& $(0.124)$ & $(0.090)$ & $(0.109)$ & $(0.114)$ \\
Treatment 3 & $1.590^{* *}$ & 1.349 & $1.413^{*}$ & 1.445 \\
& $(0.378)$ & $(0.291)$ & $(0.292)$ & $(0.337)$ \\
Treatment 4 & 1.020 & 0.938 & 1.049 & 1.009 \\
& $(0.424)$ & $(0.448)$ & $(0.507)$ & $(0.484)$ \\
Treatment 5 & $0.564^{* * *}$ & $0.462^{* * *}$ & $0.495^{* * *}$ & $0.487^{* * *}$ \\
& $(0.098)$ & $(0.077)$ & $(0.071)$ & $(0.076)$ \\
Treatment 6 & 1.087 & 1.016 & 1.104 & 1.114 \\
& $(0.370)$ & $(0.335)$ & $(0.335)$ & $(0.328)$ \\
Treatment 7 & 1.026 & 0.911 & 1.030 & 1.052 \\
& $(0.241)$ & $(0.206)$ & $(0.253)$ & $(0.229)$ \\
\hline
\end{tabular}

Note: Brackets Denote Standard Errors. ${ }^{*}=<0.100,{ }^{* *}=<0.05$, $* * *=<0.001$.

Table 6. Comparing levels of trust in Republicans to Republicans in control treatment.

\begin{tabular}{ccccc}
\hline \hline $\begin{array}{c}\text { Model Pol Party } \\
\text { Republican }\end{array}$ & $\begin{array}{c}\text { Model A } \\
\text { Odds Ratio }\end{array}$ & $\begin{array}{c}\text { Model B } \\
\text { Odds Ratio }\end{array}$ & $\begin{array}{c}\text { Model C } \\
\text { Odds Ratio }\end{array}$ & $\begin{array}{c}\text { Model D } \\
\text { Odds Ratio }\end{array}$ \\
\hline Treatment 2 & $0.878^{* *}$ & $0.906^{* *}$ & $0.862^{* * *}$ & $0.894^{* * *}$ \\
& $(0.048)$ & $(0.043)$ & $(0.023)$ & $(0.020)$ \\
Treatment 3 & 0.776 & 0.770 & 0.742 & 0.743 \\
& $(0.207)$ & $(0.181)$ & $(0.202)$ & $(0.209)$ \\
Treatment 4 & 0.689 & 0.823 & 0.894 & 1.004 \\
& $(0.520)$ & $(0.650)$ & $(0.696)$ & $(0.550)$ \\
Treatment 5 & 0.820 & 0.913 & 0.946 & 1.089 \\
& $(0.545)$ & $(0.579)$ & $(0.591)$ & $(0.486)$ \\
Treatment 6 & 1.059 & 1.266 & 1.274 & $1.549^{* *}$ \\
& $(0.329)$ & $(0.472)$ & $(0.439)$ & $(0.215)$ \\
Treatment 7 & $0.418^{* *}$ & $0.501^{*}$ & $0.552^{*}$ & $0.652^{* *}$ \\
& $(0.141)$ & $(0.060)$ & $(0.174)$ & $(0.102)$ \\
\hline
\end{tabular}

Note: Brackets Denote Standard Errors. ${ }^{*}=<0.100,{ }^{* *}=<0.05$, $* * *=<0.001$.

(Table 5, Figure 2). Consequently, for H2, I reject null; trust in liberal-oriented compared with conservativeoriented individuals will be significantly higher in response to a social cue that a partner shares similar social values for normatively flexible and egalitarian social environments.

As further predicted by the SRH, in Treatment 2, "Liberal Values," levels of trust in Republican participants decrease relative to control (Table 6). This effect reaches significance at or above the $95 \%$ confidence level $(p<0.050)$ across Models A-D. Consequently, for $H 3$, I reject null; compared with the 


\section{Social cues and ideology}

Table 7. Comparing the affect of implicit attitudes vs. shared identity on trust.

\begin{tabular}{ccccc}
\hline \hline & Model A & Model B & Model C & Model D \\
Model & Odds Ratio & Odds Ratio & Odds Ratio & Odds Ratio \\
\hline Democrats & $1.708^{* * *}$ & $1.643^{* *}$ & $1.653^{* * *}$ & $1.388^{* *}$ \\
2 vs. 6 & $(0.281)$ & $(0.324)$ & $(0.231)$ & $(0.205)$ \\
Republicans & 0.733 & 0.608 & 0.583 & $0.479^{* *}$ \\
3 vs. 6 & $(0.350)$ & $(0.308)$ & $(0.265)$ & $(0.140)$ \\
\hline
\end{tabular}

Note: Brackets Denote Standard Errors. ${ }^{*}=<0.100,{ }^{* *}=<0.05$, $* * *=<0.001$.

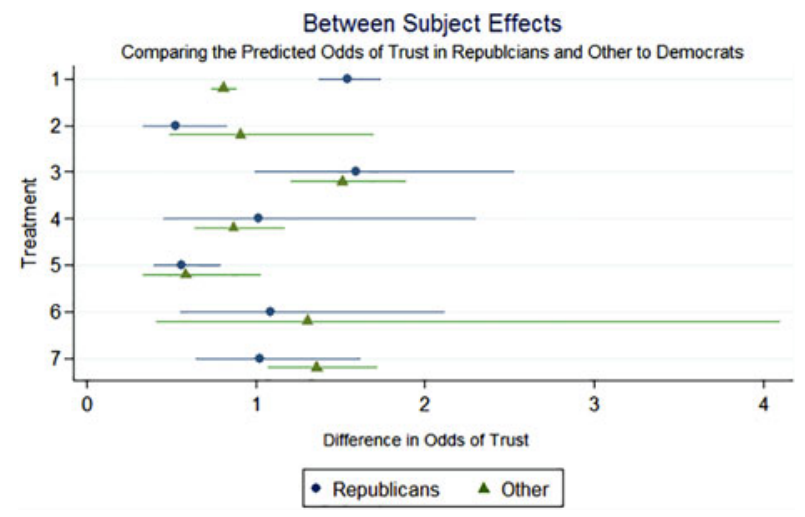

Figure 2. Figure 2 shows the difference in trust between Treatment and Control in Republicans and other as compared to the difference in trust in Democrats. See Table 6: Model A.

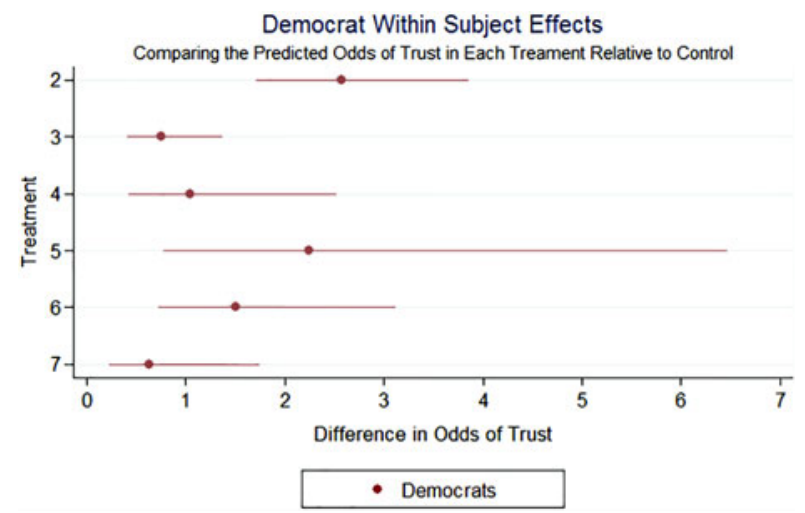

Figure 3. Figure 3 shows the difference in odds of trust between Treatment and Control in Democrats. See Table 5: Model A.

control, conservative-oriented individuals will display decreased levels of trust in response to a social cue that their partner displays dissimilar social values.

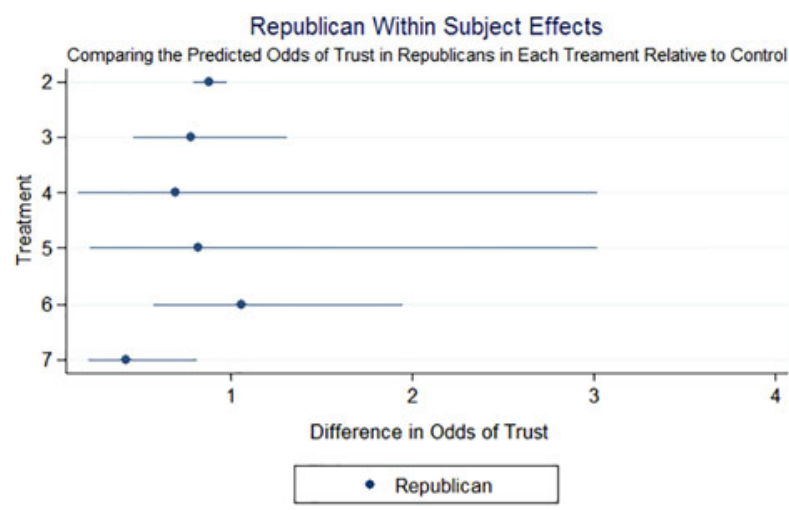

Figure 4. Figure 4 shows the difference in odds of trust between Treatment and Control in Republicans. See Table 7: Model A.

\section{Treatments 4 and 5: Left and right political identity}

In Treatments 4 and 5, participants were matched with partners who held right or left political orientations. In response to Treatment 5, "Left Political Identity," Democrat participants show an increase in levels of trust. This effect reaches significance at or above the $90 \%$ confidence level in Models B-D but fails to reach significance in Model A (Table 4). Comparing the effect of implicit attitudes in Treatment 2 against shared orientation in Treatment 5 shows that there is no significant difference in levels of trust between the two treatments relative to the control treatment (Table 8).

In response to Treatment 4, "Right Political Identity," Republican participants do not show a significant change in levels of trust (Table 6). Comparing the effect of Treatment 3, "Conservative Values," against shared orientation in Treatment 4, "Right Political Identity," (Table 8) shows no significant difference in levels of trust between the two treatments relative to the control treatment.

Treatments 6 and 7: Sport - In-Group and Sport - Out Group

In Treatment 6, "Sport - In-Group," participants were matched to a partner with a shared social identity, "a preference for a favorite sport." Looking at the between-subjects effects, no significant differences are observed between Democrats and Republicans in either Treatment 6, "Sport - In-Group" or Treatment 7, "Sport - Out-Group" relative to the control treatment. 


\section{Mansell}

Table 8. Comparing the affect of implicit attitudes vs. shared identity on trust.

\begin{tabular}{lcccc}
\hline \hline Model & $\begin{array}{c}\text { Model A } \\
\text { Odds Ratio }\end{array}$ & $\begin{array}{c}\text { Model B } \\
\text { Odds Ratio }\end{array}$ & $\begin{array}{c}\text { Model C } \\
\text { Odds Ratio }\end{array}$ & $\begin{array}{c}\text { Model D } \\
\text { Odds Ratio }\end{array}$ \\
\hline Democrats & 1.146 & 1.037 & 0.998 & 0.863 \\
2 vs. 5 & $(0.406)$ & $(0.491)$ & $(0.324)$ & $(0.098)$ \\
Republicans & 1.126 & 0.935 & 0.830 & 0.739 \\
3 vs. 4 & $(0.916)$ & $(0.798)$ & $(0.667)$ & $(0.416)$ \\
\hline
\end{tabular}

Note: Brackets Denote Standard Errors. ${ }^{*}=<0.100,{ }^{* *}=<0.05$, $* * *=<0.001$.

Looking at the within-subjects effects for Democrats and Republicans, knowledge of a shared sports preference had a positive effect on trust relative to the control treatment. However, for both Democrats and Republicans this effect only reaches significance in Model D, where it reaches significance at the $95 \%$ confidence level (Tables 4 and 6). Among Democrats, comparing the effects of Treatment 2, "Liberal Attitudes," and Treatment 6, "Sport - In-Group," on levels of trust shows that the effect of shared identity in Treatment 6 is less than the effect of attitudes for normatively flexible and egalitarian environments in Treatment 2 , relative to the control treatment. This effect reaches significance at or above the $95 \%$ confidence level across Models A-D (Table 7). Among Republicans, comparing the effects of Treatment 3, "Conservative Attitudes," attitudes for normatively stable and structured social environments, and Treatment 6, "Sport - In-Group" on levels of trust shows that the effect of conservative attitudes on trust in Treatment 3 is less than the effect of shared sports preferences in Treatment 6 (Table 7). However, this effect is only significant in Model D, where it reaches significance at the $95 \%$ confidence level.

Additionally, in Treatment 7, "Sport - Out-Group," trust in Republicans is significantly lower compared with the control treatment. While this effect reaches significance between the $90 \%$ and $95 \%$ confidence level (Table 6), some caution is required in interpreting this effect because of the small sample size in this treatment $(n=138)$.

\section{Treatment effects by implicit attitudes}

The objective of this model is to observe whether participants show a similar pattern of behavior in response to treatment as when ideological orientation is assigned based on scores on the implicit social attitudes measure compared with political party affiliation (Table 9). I focus on the within-subjects effects, comparing the effect of treatment on individuals with the same score on the attitude measure.

Participants are grouped according to their responses on each of the five attitude dimensions of the implicit attitude measures: (1) traditional moral codes, (2) outgroups/rule breakers, (3) role of individuals/group, (4) leadership, and (5) absolutes. Participants are coded as categorical variables based on their score in each of the five implicit attitude dimensions. Category 1 is associated with a strong liberal orientation. Category 1 is coded as the reference category for all five dimensions. The results show that assigning ideology by implicit attitudes produces the same basic pattern of responses to treatment as assigning ideology by political party affiliation.

Table 9 shows that in Treatment 2, trust in individuals whose scores reflect a strong liberal orientation, Category 1 , significantly increases relative to the control in each of the five attitude dimensions. This effect reaches significance at the $99 \%$ confidence level. Looking at individuals whose scores reflect a strong conservative orientation, Categories 3 and 4, a significant negative effect is observed across three of the five implicit attitude dimensions relative to the control treatment: (1) traditional moral codes, (2) out-groups/rule breakers, and (3) role of individuals/group. In the moral code and out-group dimensions, this effect reaches significance at the $95 \%$ confidence level. In the role of individuals/group dimension, this effect reaches significance at the $90 \%$ confidence level. It is noteworthy that trust also increases in Category 5 of the out-group dimensions and that this effect reaches significance at the $95 \%$ confidence level relative to the control. Category 5 of the out-group dimension is the only example in which individuals with attitudes associated with a conservative ideological orientation show a significant increase trust in response to social information. However, Category 5 of the out-group dimension also shows significant increases in trust in response to Treatments 3 and 6.

Looking at Treatment 3, trust in individuals with a strong liberal orientation, Category 1 , is not significantly different relative to the control treatment. Among individuals with a strong conservative orientation, Category 4, a significant negative effect is observed in the out-group dimension. This effect reaches significance at the $90 \%$ confidence level. Importantly, as in the regression models by political party affiliation, no negative effect is observed among liberals in response to outgroup implicit attitudes. No positive effect is observed in strong conservatives in response to in-group implicit 


\section{Social cues and ideology}

Table 9. Within-subject effects by score on the five implicit attitudes dimensions.

\begin{tabular}{|c|c|c|c|c|c|}
\hline Model & $\begin{array}{l}\text { Moral Code } \\
\text { Odds Ratio }\end{array}$ & $\begin{array}{l}\text { Outgroup } \\
\text { Odds Ratio }\end{array}$ & $\begin{array}{l}\text { Role of Group } \\
\text { Odds Ratio }\end{array}$ & $\begin{array}{l}\text { Leadership } \\
\text { Odds Ratio }\end{array}$ & $\begin{array}{c}\text { Absolute } \\
\text { Odds Ratio }\end{array}$ \\
\hline Treat 2. Cat 1 & $\begin{array}{c}3.744^{* * *} \\
(0.271)\end{array}$ & $\begin{array}{c}17.481^{* * *} \\
(11.647)\end{array}$ & $\begin{array}{c}3.668^{* * *} \\
(0.886)\end{array}$ & $\begin{array}{c}2.236^{* * *} \\
(0.142)\end{array}$ & $\begin{array}{c}2.794^{* * *} \\
(0.643)\end{array}$ \\
\hline Treat 2. Cat 2 & $\begin{array}{c}0.777 \\
(0.196)\end{array}$ & $\begin{array}{l}2.289^{*} \\
(0.989)\end{array}$ & $\begin{array}{c}1.773^{* * *} \\
(0.190)\end{array}$ & $\begin{array}{l}1.693^{*} \\
(0.491)\end{array}$ & $\begin{array}{l}1.464^{*} \\
(0.312)\end{array}$ \\
\hline Treat 2. Cat 3 & $\begin{array}{c}1.151 \\
(0.606)\end{array}$ & $\begin{array}{l}1.640 * * \\
(0.397)\end{array}$ & $\begin{array}{c}2.457^{* * *} \\
(0.461)\end{array}$ & $\begin{array}{c}1.109 \\
(0.245)\end{array}$ & $\begin{array}{c}1.229 \\
(0.317)\end{array}$ \\
\hline Treat 2. Cat 4 & $\begin{array}{c}0.839^{* *} \\
(0.062)\end{array}$ & $\begin{array}{l}0.896^{* *} \\
(0.050)\end{array}$ & $\begin{array}{l}0.739^{*} \\
(0.115)\end{array}$ & & \\
\hline Treat 2. Cat 5 & & $\begin{array}{c}2.121^{* * *} \\
(0.432)\end{array}$ & & & \\
\hline Treat 3. Cat 1 & $\begin{array}{c}0.961 \\
(0.354)\end{array}$ & $\begin{array}{c}1.196 \\
(0.749)\end{array}$ & $\begin{array}{c}0.826 \\
(0.115)\end{array}$ & $\begin{array}{c}0.690 \\
(0.215)\end{array}$ & $\begin{array}{c}1.115 \\
(0.132)\end{array}$ \\
\hline Treat 3. Cat 2 & $\begin{array}{c}0.475 \\
(0.252)\end{array}$ & $\begin{array}{c}0.639 * * * \\
(0.083)\end{array}$ & $\begin{array}{c}0.799 \\
(0.360)\end{array}$ & $\begin{array}{c}1.202 * * * \\
(0.054)\end{array}$ & $\begin{array}{c}0.859 \\
(0.146)\end{array}$ \\
\hline Treat 3. Cat 3 & $\begin{array}{c}0.711 \\
(0.277)\end{array}$ & $\begin{array}{c}0.729 \\
(0.239)\end{array}$ & $\begin{array}{c}1.080 \\
(0.378)\end{array}$ & $\begin{array}{l}1.019 \\
(0.165)\end{array}$ & $\begin{array}{c}1.011 \\
(0.224)\end{array}$ \\
\hline Treat 3. Cat 4 & $\begin{array}{c}0.952 \\
(0.415)\end{array}$ & $\begin{array}{c}0.673^{*} \\
(0.158)\end{array}$ & $\begin{array}{c}0.734 \\
(0.184)\end{array}$ & & \\
\hline Treat 3. Cat 5 & & $\begin{array}{l}1.707^{* *} \\
(0.305)\end{array}$ & & & \\
\hline Treat 4. Cat 1 & $\begin{array}{c}1.075 \\
(0.466)\end{array}$ & $\begin{array}{c}1.160 \\
(0.880)\end{array}$ & $\begin{array}{c}0.803 \\
(0.326)\end{array}$ & $\begin{array}{c}1.019 \\
(0.604)\end{array}$ & $\begin{array}{c}1.026 \\
(0.599)\end{array}$ \\
\hline Treat 4. Cat 2 & $\begin{array}{c}0.668 \\
(0.544)\end{array}$ & $\begin{array}{c}0.737 \\
(0.297)\end{array}$ & $\begin{array}{c}0.881 \\
(0.537)\end{array}$ & $\begin{array}{c}1.104 \\
(0.546)\end{array}$ & $\begin{array}{c}1.072 \\
(0.232)\end{array}$ \\
\hline Treat 4. Cat 3 & $\begin{array}{c}0.850 \\
(0.883)\end{array}$ & $\begin{array}{c}0.984 \\
(0.582)\end{array}$ & $\begin{array}{c}1.943 \\
(1.285)\end{array}$ & $\begin{array}{c}0.619 \\
(0.317)\end{array}$ & $\begin{array}{c}0.532 \\
(0.610)\end{array}$ \\
\hline Treat 4. Cat 4 & $\begin{array}{c}0.805 \\
(0.147)\end{array}$ & $\begin{array}{c}0.863 \\
(0.521)\end{array}$ & $\begin{array}{c}0.606 \\
(0.372)\end{array}$ & & \\
\hline Treat 4. Cat 5 & & $\begin{array}{c}1.392 \\
(0.681)\end{array}$ & & & \\
\hline Treat 5. Cat 1 & $\begin{array}{c}2.069 \\
(1.105)\end{array}$ & $\begin{array}{c}2.813 \\
(3.452)\end{array}$ & $\begin{array}{c}2.814 \\
(1.898)\end{array}$ & $\begin{array}{c}1.923 \\
(1.116)\end{array}$ & $\begin{array}{c}1.677 \\
(1.060)\end{array}$ \\
\hline Treat 5. Cat 2 & $\begin{array}{c}1.576 \\
(0.966)\end{array}$ & $\begin{array}{c}1.474 \\
(1.041)\end{array}$ & $\begin{array}{c}1.130 \\
(0.749)\end{array}$ & $\begin{array}{l}1.272 * \\
(0.182)\end{array}$ & $\begin{array}{c}1.670 \\
(0.595)\end{array}$ \\
\hline Treat 5. Cat 3 & $\begin{array}{c}1.074 \\
(1.009)\end{array}$ & $\begin{array}{c}1.774 \\
(0.852)\end{array}$ & $\begin{array}{c}3.086^{* *} \\
(1.326)\end{array}$ & $\begin{array}{c}0.952 \\
(1.319)\end{array}$ & $\begin{array}{c}1.163 \\
(0.708)\end{array}$ \\
\hline Treat 5. Cat 4 & $\begin{array}{l}0.762^{*} \\
(0.120)\end{array}$ & $\begin{array}{c}1.236 \\
(0.298)\end{array}$ & $\begin{array}{c}0.669 \\
(0.193)\end{array}$ & & \\
\hline Treat 5. Cat 4 & & $\begin{array}{c}1.689 \\
(0.837)\end{array}$ & & & \\
\hline Treat 6. Cat 1 & $\begin{array}{c}1.689 \\
(0.693)\end{array}$ & $\begin{array}{c}2.374 \\
(1.892)\end{array}$ & $\begin{array}{c}1.386 \\
(0.609)\end{array}$ & $\begin{array}{l}1.498 \\
(0.718)\end{array}$ & $\begin{array}{c}1.235 \\
(0.490)\end{array}$ \\
\hline Treat 6. Cat 2 & $\begin{array}{c}1.225 \\
(1.272)\end{array}$ & $\begin{array}{c}1.141 \\
(0.356)\end{array}$ & $\begin{array}{c}1.372 \\
(0.996)\end{array}$ & $\begin{array}{c}1.747 \\
(0.806)\end{array}$ & $\begin{array}{c}2.163^{*} \\
(0.980)\end{array}$ \\
\hline Treat 6. Cat 3 & $\begin{array}{c}1.813 \\
(1.561)\end{array}$ & $\begin{array}{c}1,514 \\
(0.420)\end{array}$ & $\begin{array}{l}2.792^{*} \\
(1.491)\end{array}$ & $\begin{array}{c}1.574 \\
(1.268)\end{array}$ & $\begin{array}{c}1.774 \\
(0.780)\end{array}$ \\
\hline Treat 6. Cat 4 & $\begin{array}{l}1.010 \\
(0.309)\end{array}$ & $\begin{array}{c}1.243 \\
(0.710)\end{array}$ & $\begin{array}{c}0.975 \\
(0.076)\end{array}$ & & \\
\hline Treat 6. Cat 4. & & $\begin{array}{l}2.293^{*} \\
(1.086)\end{array}$ & & & \\
\hline
\end{tabular}




\section{Mansell}

Table 9. (Continued.)

\begin{tabular}{|c|c|c|c|c|c|}
\hline Model & $\begin{array}{l}\text { Moral Code } \\
\text { Odds Ratio }\end{array}$ & $\begin{array}{l}\text { Outgroup } \\
\text { Odds Ratio }\end{array}$ & $\begin{array}{l}\text { Role of Group } \\
\text { Odds Ratio }\end{array}$ & $\begin{array}{l}\text { Leadership } \\
\text { Odds Ratio }\end{array}$ & $\begin{array}{c}\text { Absolute } \\
\text { Odds Ratio }\end{array}$ \\
\hline Treat 7. Cat 1 & $\begin{array}{c}1.484 \\
(1.051)\end{array}$ & $\begin{array}{c}0.762 \\
(0.808)\end{array}$ & $\begin{array}{c}0.690 \\
(0.244)\end{array}$ & $\begin{array}{c}0.770 \\
(0.455)\end{array}$ & $\begin{array}{c}0.937 \\
(0.439)\end{array}$ \\
\hline Treat 7. Cat 2 & $\begin{array}{c}0.118^{* * *} \\
(0.056)\end{array}$ & $\begin{array}{c}0.691 \\
(0.281)\end{array}$ & $\begin{array}{l}0.515 \\
(0.511)\end{array}$ & $\begin{array}{c}0.615 \\
(0.254)\end{array}$ & $\begin{array}{l}0.403^{*} \\
(0.199)\end{array}$ \\
\hline Treat 7. Cat 3 & $\begin{array}{c}0.324 \\
(0.295)\end{array}$ & $\begin{array}{c}0.463 \\
(0.391)\end{array}$ & $\begin{array}{l}1.045 \\
(0.752)\end{array}$ & $\begin{array}{c}0.219^{* *} \\
(0.171)\end{array}$ & $\begin{array}{c}0.495 \\
(0.304)\end{array}$ \\
\hline \multirow[t]{2}{*}{ Treat 7. Cat 4} & $\begin{array}{c}0.420 \\
(0.242)\end{array}$ & $\begin{array}{c}0.574 \\
(0.290)\end{array}$ & $\begin{array}{c}0.443^{* * *} \\
(0.029)\end{array}$ & & \\
\hline & & $\begin{array}{l}1.092 \\
(0.118)\end{array}$ & & & \\
\hline
\end{tabular}

Note: Brackets Denote Standard Errors. ${ }^{*}=<0.100,{ }^{* *}=<0.05,{ }^{* * *}=<0.001$.

attitudes, with one exception. A positive increase in trust in observed in Category 5 of the out-group dimension. This effect reaches significance at the $95 \%$ confidence level.

Taken together, with the exception of Category 5 of the out-group dimension individuals with a strong conservative social attitudes, Category 4 , did not show a significant increase in trust in response to social information, further supporting the interpretation of the SRH, but did show several significant negative effects. Similarly, individuals with a strong liberal orientation, Category 1, showed several significant positive effects in response to social information, but no significant negative effects. These results are consistent with the predictions of the SRH.

\section{Discussion}

In this article, I investigated the possible evolutionary influences on ideological differences. Drawing from previous research on the behavioral traits associated with ideological differences, including differences in cognition and decision-making, I developed the social risk hypothesis, which postulated that differences in social values associated with different ideological orientations reflect alternative adaptive strategies to maximize returns from social interactions. I then tested this hypothesis using an experimental interaction, a trust game, in which participants received information that a potential partner has similar or dissimilar social values. Within the SRH adaptation refers to the utility of a trait to produce beneficial social outcomes in response to different environmental conditions. As the product of adaptive strategies, the SRH predicts that liberal participants maximize their social returns by increasing their likelihood of trusting an anonymous partner in response to a positive cue (maximizing their potential gains), while conservative participants maximize their social returns by decreasing their likelihood of trusting an anonymous partner in response to a negative cue (minimizing their potential losses).

As predicted by the SRH, Democrats display higher levels of trust in response to knowledge that a social partner preferred a normatively flexible and egalitarian social environment, while trust in Republicans decreases in response to the same social information. While Democrats show several consistent and significant increases in trust relative to the control, no consistent and significant increases in trust are observed in Republicans (although a positive trend is observed in Treatment 6). Also, consistent with the SRH, Republicans show several significant negative effects, the most consistent and significant of which are in response to Treatment 2, "Liberal Values," and Treatment 7, "Sport — Out-Group." No significant negative effects are observed in Democrats. Importantly, these same basic trends are replicated when ideological orientation is assigned based on individuals' scores on the attitude measure. Trust in liberal-oriented individuals significantly increases in response to a positive social cue but did not significantly decrease in response to a negative cue. Similarly, with the exception of Category 5 of the out-group dimension, trust in conservative-oriented individuals did not significantly increase in response to a positive social cue but did significantly decrease in response to negative cues. 


\section{Social cues and ideology}

In addition to the predicted outcomes in the control treatment, trust in Republicans is significantly higher than in Democrats. This observation appears to be contrary to literature, including the theory of motivated social cognition, which demonstrates a greater sensitivity to external threat and social out-groups in individuals with conservative ideological orientations. ${ }^{2,23,68,69}$ Based on this literature, the intuition is that, when matched with an anonymous partner, trust in conservative individuals should be less than or equal to that of liberal individuals. However, there are several possibilities to account for this observed effect. It is possible that, in the absence of a salient social cue about an individual's identity or intention, being asked to interact with an anonymous partner may not constitute significant threat for conservative individuals. It is consistent with the argument of the SRH that ideological differences reflect alternative adaptive social strategies that the greater sensitivity to negative cues, such as external threats, reflects a valence of specific types of social environmental stimuli and not a general distrust of social interaction. Concerning the causes of the effect, the focus of the experiment on response to treatment allows for limited conclusions; however, assuming this result is a not a product of sampling error, two possibilities present themselves. First, from the perspective of an adaptive social strategy, it is logical that individuals with a disposition toward social interaction would develop a mechanism to identify and avoid untrustworthy social partners. Alternatively, greater levels of social interaction by conservatives in the control conditions could be a product of preferences for normatively stable and structured social environments, as social interactions and rituals within these environments are often structured, normative, or habitualized. A study on cooperative behavior by Sosis and Ruffle finds that conservative individuals who live in highly ordered and structured environments display higher levels of social generosity toward an anonymous social partner in comparison to individuals in non-structured groups. ${ }^{70}$ Factoring in the tendency for conservative individuals to rely on habitual behavioral responses under novel conditions, conservative individuals may be more likely to initially trust because this represents a normal outcome. In either case, further study is required to determine the robustness of this effect and whether it is a consequence of a behavioral disposition or social habit.

Overall, this project makes two important contributions to the understanding of ideological orientation.
First, it provides important information about how the behavioral traits associated with liberal and conservative ideological orientations interact with the social environment to influence behavior. Second, it lays a foundation for future studies to investigate the possible evolutionary influences to the ideological spectrum, in particular, whether the different traits associated with liberal and conservative orientations reflect socio-environmental adaptations.

These initial results provide strong support for the SRH; however, further consideration should be given to separating strong in-group effects associated with shared social and ideological identity from sensitivity to fairness/inequality. Specifically, it is important to determine whether liberal participants are experiencing a positive response to a strong in-group social cue, in the form of the rich implicit attitude measure, or whether they are employing an adaptive strategy that is sensitive to positive social indicators.

A second problem, which stems from the usage of implicit attitudes as social cues, is that the content of these attitudes may produce differences in demand effects in liberals and conservatives. Demand effects refer "to changes in behavior by experimental subjects due to cues about what constitutes appropriate behaviour." 71 For example, the phrase "We realize that people everywhere deserve our help" may prime individuals about expectations about appropriate behavior (e.g., trust) more than a statement such as "We take care of our own people first." As this experiment does not directly control for differences in demand effects in liberals and conservatives (it does control for this indirectly through the use of a multiple treatment design), it is possible that the higher levels of trust in liberals in response to implicit attitudes is being driven by differences in sensitivity to expectations about what is considered to be appropriate behavior. Similarly, by relaying information about partners' preferences for the structure and function of the social group, such as preferences for social fairness and egalitarianism, implicit attitudes may be creating expectations about the likelihood that a partner will reciprocate. Consequently, the differences in levels of trust between Treatment 2, "Liberal Values," and Treatment 3, "Conservative Values," may be driven by the expectation that partners with liberal implicit attitudes are more likely to reciprocate. Importantly, while demand effects present a possible confound to the argument that liberal and conservative orientations are caused by differential sensitivity to positive and negative cues, the influence of demand effects does not preclude 


\section{Mansell}

the influence of evolutionary selection on ideological differences. Rather, it may be that the underlying mechanism is different. For example, a greater sensitivity to statements such as "We realize that people everywhere deserve our help" may reflect different strategies involving levels of empathy, altruism, or other emotional states. This conclusion is also consistent with research findings by Schreiber et al. that liberals and conservatives differ in cognitive flexibility and decision-making related to the processing or monitoring of different emotional states.

Finally, by relying on an online sample this study may be under representing individuals with strong conservative ideological orientation who, as a consequence of their established dispositions, may be less likely to participate in online research. This could bias the results of the study if individuals with strong conservative orientations are more likely to positively respond to cues that a potential social partner share similar social values. While this conclusion is not supported by the results in current literature on the cognitive behaviors of conservative individuals, or by the findings of this study, to ensure the rigor of the empirical process, it is important that this possibility be given further consideration.

To address these concerns, I plan to revisit the predictions of the SRH in two further experiments that directly manipulate the effects of inequality and social change on levels of group cooperation. In doing so, I control for confounding effects linked to shared group identity, and the complexity of social attitudes. In the first of these experiments, I focus exclusively on the effects of fairness and group inequality on individuals' contributions to a communal good. Following from the framework of the SRH that liberal and conservative ideological orientations are based on strategies to obtain reciprocity and avoid exploitation, I predict that liberals and conservatives will show similar levels of cooperation in groups in which there is a social inequality; however, when individuals within the group vote to redress this inequality I predict that cooperation in liberals, but not conservatives, will significantly increase.

In the second of these experiments, I focus on the effects of normatively unstable or conflicted environments on individuals' contributions to a communal good. Again, following from the framework of the SRH, I predict that cooperation in conservative individuals will be more sensitive to conditions of social agreement and disagreement. In particular, I predict that cooperation in conservatives, but not liberals, will decrease when they are assigned to a social group in which the majority of individuals disagree with their perspective about a normative violation.

\section{References}

1. A. S. Gerber, G. A. Huber, D. Doherty, C. M. Dowling, and S. E. Ha, "Personality and political attitudes: Relationships across issue domains and political contexts," American Political Science Review, 2010, 104(1): 111-133.

2. D. R. Oxley, K. B. Smith, J. R. Alford, M. V. Hibbing, J. L. Miller, M. Scalora, P. K. Hatemi, and J. R. Hibbing, "Political attitudes vary with physiological traits," Science, 2008, 321(5896): 1667-1670.

3. N. J. Shook and R. H. Fazio, "Political ideology, exploration of novel stimuli, and attitude formation," Journal of Experimental Social Psychology, 2009, 45(4): 995-998.

4. D. M. Amodio, J. T. Jost, S. L. Master, and C. M. Yee, "Neurocognitive correlates of liberalism and conservatism," Nature Neuroscience, 2007, 10(10): 1246-1247.

5. R. Kanai, T. Feilden, C. Firth, and G. Rees, "Political orientations are correlated with brain structure in young adults," Current Biology, 2011, 21(8): 677-680.

6. D. Schreiber, G. Fonzo, A. N. Simmons, C. T. Dawes, T. Flagan, J. H. Fowler, and M. P. Paulus, "Red brain, blue brain: Evaluative processes differ in Democrats and Republicans," PLOS ONE, 2013, 8(2): e52970.

7. P. K. Hatemi, S. E. Medland, R. Klemmensen, S. Oskarsson, L. Littvay, C. T. Dawes, and B. Verhulst et al., "Genetic influences on political ideologies: Twin analyses of 19 measures of political ideologies from five democracies and genome-wide findings from three populations," Behavior Genetics, 2014, 44(3): 282-294.

8. J. H. Fowler and C. T. Dawes, "In defense of genopolitics," American Political Science Review, 2013, 107(2): 362-374.

9. J. H. Fowler and C. T. Dawes, "Two genes predict voter turnout," Journal of Politics, 2008, 70(3): 579-594.

10. P. K. Hatemi, J. R. Alford, J. R. Hibbing, N. G. Martin, and L. J. Eaves, "Is there a 'party' in your genes?" Political Research Quarterly, 62(3): 584-600.

11. P. K. Hatemi, N. A. Gillespie, L. J. Eaves, B. S. Maher, B. T. Webb, A. C. Heath, and S. E. Medland et al., "A genome-wide analysis of liberal and conservative political attitudes," Journal of Politics, 2011, 73(1): 271-285.

12. J. R. Hibbing, K. B. Smith, and J. R. Alford, "Differences in negativity bias underlie variations in political ideology," Behavioral and Brain Sciences, 2014, 37(3): 297-307. 


\section{Social cues and ideology}

13. P. K. Hatemi and R. McDermott, Man Is by Nature a Political Animal: Evolution, Biology, and Politics (Chicago: University of Chicago Press, 2011).

14. M. B. Petersen, "Public opinion and evolved heuristics: The role of category-based inference," Journal of Cognition and Culture, 2009, 9(3): 367-389.

15. G. V. Caprara, S. Schwartz, C. Capanna, M. Vecchione, and C. Barbaranelli, "Personality and politics: Values, traits, and political choice," Political Psychology, 2006, 27(1): 1-28.

16. G. V. Caprara and P. G. Zimbardo, "Personalizing politics: A congruency model of political preference," American Psychologist, 2004, 59(7): 581-594.

17. Y. Piurko, S. H. Schwartz, and E. Davidov, "Basic personal values and the meaning of left]right political orientations in 20 countries," Political Psychology, 2011, 32(4): 537-561.

18. S. H. Schwartz, G. V. Caprara, and M. Vecchione, "Basic personal values, core political values, and voting: A longitudinal analysis," Political Psychology, 2010, 31(3): 421-452.

19. Piurko, Schwartz, and Davidov.

20. H. Thorisdottir, J. T. Jost, I. Liviatan, and P. E. Shrout, "Psychological needs and values underlying left-right political orientation: Cross-national evidence from Eastern and Western Europe," Public Opinion Quarterly, 2007, 71(2): 175-203.

21. J. T. Jost, "The end of the end of ideology," American Psychologist, 2006, 61(7): 651-670.

22. J. T. Jost, C. M. Federico, and J. L. Napier, "Political ideology: Its structure, functions, and elective affinities," Annual Review of Psychology, 2009, 60: 307-337.

23. J. T. Jost, J. Glaser, A. W. Kruglanski, and F. J. Sulloway, "Political conservatism as motivated social cognition," Psychological Bulletin, 2003, 129(3): 339-375.

24. Petersen.

25. K. B. Smith, D. R. Oxley, M. V. Hibbing, J. R. Alford, and J. R. Hibbing, "Linking genetics and political attitudes: Reconceptualizing political ideology," Political Psychology, 2011, 32(3): 369-397.

26. Hatemi, Medland et al.

27. J. R. Alford, C. L. Funk, and J. R. Hibbing, "Beyond liberals and conservatives to political genotypes and phenotypes," Perspectives on Politics, 2008, 6(2): 321-328.

28. J. R. Alford, C. L. Funk, and J. R. Hibbing, "Are political orientations genetically transmitted?" American Political Science Review, 2005, 99(2): 153-167.
29. Fowler and Dawes, 2013.

30. Hatemi, Gillespie et al.

31. P. K. Hatemi, J. R. Hibbing, S. E. Medland, M. C. Keller, J. R. Alford, K. B. Smith, N. G. Martin, and L. J. Eaves, "Not by twins alone: Using the extended family design to investigate genetic influence on political beliefs," American Journal of Political Science, 2010, 54(3): 798-814.

32. E. Bell, J. A. Schermer, and P. A. Vernon, "The origins of political attitudes and behaviours: An analysis using twins," Canadian Journal of Political Science/Revue canadienne de science politique, 2009, 42(4): 855-879.

33. Amodio et al.

34. Shook and Fazio.

35. M. A. Nowak, "Five rules for the evolution of cooperation," Science, 2006, 314(5805): 1560-1563.

36. M. Van Vugt, "Evolutionary origins of leadership and followership," Personality and Social Psychology Review, 2006, 10(4): 354-371.

37. R. L. Trivers, "The evolution of reciprocal altruism," Quarterly Review of Biology, 1971, 46(1): 35-57.

38. J. T. Jost and D. M. Amodio, "Political ideology as motivated social cognition: Behavioral and neuroscientific evidence," Motivation and Emotion, 2012, 36(1): 55-64.

39. D. Green and I. Shapiro, Pathologies of Rational Choice Theory: A Critique of Applications in Political Science (New Haven, CT: Yale University Press, 1996).

40. J. T. Jost, “Elective affinities': On the psychological bases of left-right differences," Psychological Inquiry, 2009, 20(2-3): 129-141.

41. S. Tomkins, "Left and right: A basic dimension of ideology and personality," in The Study of Lives: Essays on Personality in Honor of Henry A. Murray, R. W. White and K. F. Bruner, eds. (New York: Atherton Press, 1963), pp. 388-411.

42. Jost, Federico, and Napier, p. 990.

43. M. Takezawa and Michael E. Price, "Revisiting 'The evolution of reciprocity in sizable groups': Continuous reciprocity in the repeated n-person prisoner's dilemma," Journal of Theoretical Biology, 2010, 264(2): 188-196.

44. H. Gintis, E. A. Smith, and S. Bowles, "Costly signaling and cooperation," Journal of Theoretical Biology, 2001, 213(1): 103-119.

45. M. A. Nowak and K. Sigmund, "Evolution of indirect reciprocity,” Nature, 2005, 437(7063): 1291-1298. 


\section{Mansell}

46. R. Boyd, H. Gintis, S. Bowles, and P. J. Richerson, "The evolution of altruistic punishment," Proceedings of the National Academy of Sciences, 2003, 100(6): 3531-3535.

47. M. E. Price, "Monitoring, reputation, and 'Greenbeard' reciprocity in a Shuar work team," Journal of Organizational Behavior, 2006, 27(2): 201-219.

48. R. Sosis, "Religion and intragroup cooperation: Preliminary results of a comparative analysis of utopian communities," Cross-Cultural Research, 2000, 34(1): 70-87.

49. T. Yamagishi, N. Jin, and T. Kiyonari, "Bounded generalized reciprocity: Ingroup boasting and ingroup favoritism," Advances in Group Processes, 1999, 16(1): 161-197.

50. J. Tooby, L. Cosmides, and M. E. Price, "Cognitive adaptations for n-person exchange: The evolutionary roots of organizational behavior," Managerial and Decision Economics, 2006, 27(2-3): 103-129.

51. Van Vugt.

52. L. R. Anderson, J. M. Mellor, and J. Milyo, "Inequality and public good provision: An experimental analysis," Journal of Socio-Economics, 2008, 37(3): 1010-1028.

53. S. A. West, A. Gardner, D. M. Shuker, T. Reynolds, M. Burton-Chellow, E. M. Sykes, M. A. Guinnee, and A. S. Griffin, "Cooperation and the scale of competition in humans," Current Biology, 2006, 16(11): 1103-1106.

54. E. A. Smith and B. Winterhalder, "Natural selection and decision-making: Some fundamental principles," in Evolutionary Ecology and Human Behavior, E. A. Smith and B. Winterhalder, eds. (New York: Aldine de Gruyter, 1992), pp. 25-60.

55. D. Shultziner, "Genes and politics: A new explanation and evaluation of twin study results and association studies in political science," Political Analysis, 2013, 21(3): $350-367$.

56. C. K. De Dreu, “Oxytocin modulates cooperation within and competition between groups: An integrative review and research agenda," Hormones and Behavior, 2012, 61(3): 419-428.

57. West et al.

58. K. A. McCabe, M. L. Rigdon, and V. L. Smith, "Positive reciprocity and intentions in trust games," Journal of Economic Behavior \& Organization, 2003, 52(2): 267-275.

59. B. Hare, A. P. Melis, V. Woods, S. Hastings, and R. Wrangham, "Tolerance allows bonobos to outperform chimpanzees on a cooperative task," Current Biology, 2007, 17(7): 619-623.

60. Tooby, Cosmides, and Price.

61. R. McElreath and P. Strimling, "How noisy information and individual asymmetries can make 'personality' an adaptation: A simple model," Animal Behaviour, 72(5): 1135-1139.

62. T. Yamagishi and Nobuhiro Mifune, "Does shared group membership promote altruism? Fear, greed, and reputation," Rationality and Society, 2008, 20(1): 5-30.

63. S. D. Gosling, P. J. Rentfrow, and W. B. Swann, "A very brief measure of the big-five personality domains," Journal of Research in Personality, 2003, 37(6): 504-528.

64. R. J. Larsen and E. Diener, "A multitrait-multimethod examination of affect structure: Hedonic level and emotional intensity," Personality and Individual Differences, 1985, 6(5): 631-636.

65. A. J. Berinsky, G. A. Huber, and G. S. Lenz, "Evaluating online labor markets for experimental research: Amazon.com's Mechanical Turk," Political Analysis, 2012, 20(3): 351-368.

66. P. Beramendi, R. R. Duch, and A. Matsuo, When lab subjects meet real people: Comparing different modes of experiments," December 25, 2014, https://cess-web.nuff.o x.ac.uk/files/pdfs/working_papers/CESS_DP2014_003.pdf (accessed January 30, 2018).

67. M. Levendusky, The Partisan Sort: How Liberals Became Democrats and Conservatives Became Republicans (Chicago: University of Chicago Press, 2009).

68. F. Asbrock, C. G. Sibley, and J. Duckitt, "Right-wing authoritarianism and social dominance orientation and the dimensions of generalized prejudice: A longitudinal test," European Journal of Personality, 2010, 24(4): 324-340.

69. J. Duckitt and K. Fisher, "The impact of social threat on worldview and ideological attitudes," Political Psychology, 2003, 24(1): 199-222.

70. R. Sosis and B. J. Ruffle, "Ideology, religion, and the evolution of cooperation: Field experiments on Israeli kibbutzim," Research in Economic Anthropology, 2004, 23: 89-117.

71. D. J. Zizzo, "Experimenter demand effects in economic experiments," Experimental Economics, 2010, 13(1): 75-98, at p. 76. 